\title{
A STUDY ON THE ROLE OF GREEN CHEMISTRY IN DAILY LIFE OF SECONDARY SCHOOL STUDENTS
}

\author{
Dr Sajeena S. \\ Principal \\ H.K.M. College of Education \\ (Affiliated to University of Kerala)
}

\begin{abstract}
The present study was intended to find the role of green chemistry in daily life application for developing environmental awareness among secondary school students. By conducting the study, the investigator found that there was an average awareness of the concept of green chemistry for secondary school students that is, $80 \%$ of the secondary school students has an average level of awareness on the concept of green chemistry and $64 \%$ of the students have average level of awareness about the daily life application of green chemistry. The findings have revealed that secondary school students are interested to incorporate green chemistry as part of their curriculum.
\end{abstract}

Keywords: Green Chemistry, daily life applications of green chemistry

\section{INTRODUCTION}

Green chemistry is the new and rapid developing branch of chemistry. The introduction of green chemistry is considered as a counter to the need to trim down the harm of the environment by synthetic products and the procedures used to produce them. Green chemistry could incorporate anything from reducing waste to even discarding waste in the right way. Every chemical waste ought to be disposed of in the best possible way without causing any harm to the eco-system and mankind. The Green Chemistry is a perfect fit for a school curriculum committed to the well-being of its responsible citizens with core human values. The principles of Green Chemistry that can energize our classrooms and bring long-term meaning and direction to a component of academic research await clear definition.

Green Chemistry is a pro-active approach to pollution prevention. It targets pollution at the design stage, before it even begins. If chemists are taught to develop products and materials in a manner that does not use hazardous substances, then much waste, hazards and cost can be avoided. Green Chemistry is designing chemical products and processes that reduce or eliminate the use and/or the generation of hazardous substances. The term "Green Chemistry", as adopted by the IUPAC Working Party on Synthetic Pathways and Processes in Green Chemistry, is defined as: "The invention, design and application of chemical products and processes to reduce or to eliminate the use and generation of hazardous substances".

Both environmental science and green chemistry seek to make the world a better place. The two are complimentary to each other. Environmental Science identifies sources, elucidates mechanisms and quantifies problems in the earth's environment. Green Chemistry seeks to solve these problems by creating alternative, safe technologies. Green Chemistry is not Environmental Chemistry. Green Chemistry targets pollution prevention at the source, during the design stage of a chemical product or process, and thus prevents pollution before it begins.

With the expansion of science, green chemistry has changed our life style. This paper presents selected examples of implementation of green chemistry principles in everyday life and in domestic purpose. Some application of green chemistry in daily life are washing with water may shrink or stretch or be spoil in some other way several clothes which are made of fabrics. These clothes should be 'dry-cleaned'. In fact, dry cleaning is not dry at all. In dry-cleaning solvents other than water are used to do the cleaning.

\section{NEED AND SIGNIFICANCE OF THE STUDY}

In the world where environmental degradation is taking on alarming levels, understanding, and acting to minimize the individual environmental impacts is an important goal for many science educators. Today's students are future citizens. So that including green chemistry in students' curriculum make them aware about the value of protecting environment and using reusable products and making a pollution free earth. Green chemistry reduces pollution at its source by minimizing or eliminating the hazards of chemical feed stocks, reagents, solvents, and products. This is unlike cleaning up pollution, which involves treating waste 


\section{International Journal of Engineering Applied Sciences and Technology, 2021 \\ Vol. 6, Issue 3, ISSN No. 2455-2143, Pages 340-345 \\ Published Online July 2021 in IJEAST (http://www.ijeast.com)}

streams or cleanup of environmental spills and other releases. Remediation may include separating hazardous chemicals from other materials, then treating them so they are no longer hazardous or concentrating them for safe disposal. Most remediation activities do not involve green chemistry. Remediation removes hazardous materials from the environment; on the other hand, green chemistry keeps the hazardous materials out of the environment in the first place.

Green Chemistry is an ideal focus for school science education because it presents a modern version of the traditional Chemistry curriculum; uses less toxic materials, making experiments safer for students; teaches critical thinking skills; reduces cost with less expensive solvents and Equipment and fewer toxic waste disposal fees; merges scientific concepts with sustainability and responsible human; gives school students opportunities to participate in meaningful science fair and projects.

Chemistry educators have a responsibility to teach students about the essential role the field of chemistry has in a sustainable future for the planet. Chemical products, such as pharmaceuticals, plastics, electronics, agrochemicals, and building materials, all benefit society yet unintended consequences resulting from the production and use of these products compel chemists to develop new technologies which minimize their harm.

Green Chemistry is an ideal focus for school science education because it presents a modern version of the traditional chemistry curriculum. With the advent of green chemistry, the experiments can be conducted with less toxic materials so that the experiments become safer for students. If green chemistry concepts are introduced in to the school curriculum the students can be taught with improving their critical thinking skills. It reduces cost with less expensive solvents and equipment and fewer toxic waste disposal fees; it can merge scientific concepts with sustainability and responsible human and also can give school students the opportunities to participate in meaningful science fair and projects. Thus, the inclusion of green chemistry in the secondary school curriculum has much relevance.

Green chemistry is a student-centered active learning approach of teaching chemistry content in an eco-friendly way. According to Haack et al. (2005), green chemistry is a useful tool to increase awareness and teach sophisticated problem-solving skills through the content of chemistry. Green chemistry is interdisciplinary in nature and involves exploration of the environment. Hence, it can serve as a theme to facilitate integrative and interdisciplinary learning experiences where students use their critical thinking and communication skills to address complex problems facing the chemical enterprise. The present study is very significant because of the significance of green chemistry.

Dhage (2013) conducted a research on "Application of Green Chemistry Principles in Daily Life". This article presents selected examples of implementation of green chemistry principle in everyday life.

Chhangani and Hussain (2018) conducted a study on topic "Green Chemistry in Everyday Life: A Healthy Way of Life". This paper attempted 10 study cases of execution of green chemistry principle in day-to-day life.

Jaiswal, Deepanshu Kapoor, Abhishek Kumar, and Kusum Sharma (2017) conducted a study on the "Application of Green Chemistry". This study explains ideology, certain examples and application of green chemistry in everyday life, in industries, laboratories, and education.

Karpudewan, Zurida, and Morita Mohamed (2010) conducted a study on "Green Chemistry: Educating Prospective Science Teachers in Education for Sustainable Development at the School of Educational Studies USM". The study has been shown that it is possible by educational to encourage the inculcation of positive environmental values for active participation of future citizens as members of the community.

Agbayewa, Olsutegbe, Alake (2013) conducted a study on "Incorporating Green Chemistry Concept into the Senior Secondary School Curriculum”. This study has been shown that there is a long term benefits of producing chemists and industrialists who would enforce greener policies and work for safer environment.

\section{STATEMENT OF THE PROBLEM}

The present study is entitled as A Study on the Role of Green Chemistry in Daily Life of Secondary School Students.

\section{OPERATIONAL DEFENITIONS}

Green Chemistry: Design of chemical products and processes that reduce or eliminate the use or generation of substances hazardous to humans, animals, plants, and the environment. The environmental protection agency (EPA) defines green chemistry, as the design of chemical products and processes that reduce or eradicate the use or generation of hazardous substances.

Secondary School Students: The students who belongs to age group of $13+$ 
International Journal of Engineering Applied Sciences and Technology, 2021

Vol. 6, Issue 3, ISSN No. 2455-2143, Pages 340-345

Published Online July 2021 in IJEAST (http://www.ijeast.com)

\section{OBJECTIVES OF THE STUDY}

1. To estimate the level of awareness of secondary school students about the concept of green chemistry.

2. To find out the level of awareness of secondary school students about daily life application of green chemistry.

\section{HYPOTHESES OF THE STUDY}

1. Secondary school students have a less awareness about the concept of green chemistry

2. Secondary school students have a less awareness about the daily life applications of green chemistry

\section{METHODOLOGY}

The population of the present study is the secondary school students of Kerala, as the study is intended to find out the role of green chemistry for developing environmental awareness among secondary school students. The sample selected for the study was 50 secondary school students from Trivandrum district.

Distribution of sample on the basis of gender is shown in the figure 1

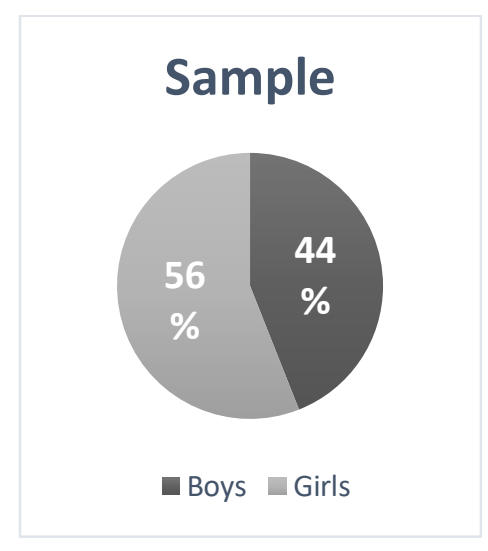

Fig 1: Percentage of boys and girls selected for the study

\section{METHODOLOGY}

\section{Method adopted for the study}

The investigator adopted survey method for the study.

\section{Tools used for the study}

Investigator prepared a questionnaire to measure the awareness of secondary school students towards green chemistry and its applications in daily life. 25 questions were prepared by the investigator. Questions 1to 13 were for checking the awareness towards green chemistry, and Questions from 14 to 25 were for checking their awareness about the daily life applications of green chemistry.

\section{Sample selected for the study}

The investigator selected 50 students from Government H S S Kazhakkuttom, Trivandrum as sample.

\section{Procedure adopted for the study}

The investigator prepared a questionnaire consisting of 25 questions was administrated to a sample of 50 secondary school students of Govt. H S S Kazhakuttom to find the level of awareness of secondary school students about the concept of green chemistry and its application in daily life.

\section{Statistical techniques employed}

Percentage analysis, mean, median, mode and SD

\section{ANALYSIS AND INTERPRETATIONS}

Table 1

Descriptive Statistics of the Sample

\begin{tabular}{|l|c|c|c|c|}
\hline & Mean & Median & Mode & SD \\
\hline Awareness on Green Chemistry & 6.24 & 7 & 7 & 1.89 \\
\hline $\begin{array}{l}\text { Daily life applications of Green } \\
\text { Chemistry }\end{array}$ & 4.86 & 5 & 5 & 1.69 \\
\hline
\end{tabular}

In order to find out the level of awareness on green chemistry and also on the daily life applications of green chemistry, the (Mean \pm SD) values were found out. In the case of the daily life application of green chemistry, the lower value was 4 and higher value was 8 , so the values coming under 4 were taken under the low awareness category, in between 4 and 8 were taken under average awareness category and scores above 8 were taken under the high awareness category. 


\section{International Journal of Engineering Applied Sciences and Technology, 2021 \\ Vol. 6, Issue 3, ISSN No. 2455-2143, Pages 340-345 \\ Published Online July 2021 in IJEAST (http://www.ijeast.com)}

In the case of awareness on the daily applications of green chemistry, the lower value obtained was 3 and upper was 7, by using the relation (Mean \pm SD). The responses coming under 3 were taken as the low awareness category, the scores obtained between 3 and 7 were taken as average awareness category and the scores above 7 were taken under high awareness category.

Table 2

Percentage of Students with Low, Average and High Awareness on Green Chemistry and on the Daily Applications of Green Chemistry

\begin{tabular}{|l|c|c|c|c|c|c|}
\hline & Low & $\%$ & Average & $\%$ & High & $\%$ \\
\hline Level of awareness on Green Chemistry & 6 & 12 & 40 & 80 & 4 & 8 \\
\hline $\begin{array}{l}\text { Level of awareness on daily life } \\
\text { applications of Green Chemistry }\end{array}$ & 10 & 20 & 32 & 64 & 8 & 16 \\
\hline
\end{tabular}

From the Table 2 it is clear that the level of awareness of secondary school students towards the green chemistry and its daily life applications are falling under the average level only.

From the percentage analysis it was clear that $92 \%$ of the students had a knowledge that green chemistry made use of a reusable methods to speed up a reaction and $90 \%$ of the students heard about biodiesel which is also a contribution of green chemistry. Only $8 \%$ of the students thought that green chemistry has some drawbacks. $82 \%$ of the students preferred chemical substances to bio products and $80 \%$ of the students agreed with making green chemistry a part of their curriculum. Only $14 \%$ of the students were aware of the environmental problems around them.

Most of the students have a knowledge that green chemistry make use of reusable methods to speed up a reaction and they have heard about the biodiesel that is a contribution of green chemistry. And a few students were with an opinion that green chemistry also have some drawbacks. most of the students prefer chemical substances to bio products and they agree on making green chemistry as a part of their curriculum.

\section{MAJOR FINDINGS OF THE STUDY}

The major findings derived from the study were as follows:

- It was found that $80 \%$ of the students have average level of awareness towards green chemistry

- It was found that $64 \%$ of the students have average level of awareness on daily life application of green chemistry.

- It was found that $80 \%$ of the students agree with making green chemistry as their part of curriculum.

- It was found that secondary school students have an average level of awareness on green chemistry and its daily life applications.

\section{TENABILITY OF HYPOTHESES}

\begin{tabular}{|c|l|c|}
\hline Sl. No. & \multicolumn{1}{|c|}{ Hypotheses } & Tenability \\
\hline 1. & $\begin{array}{l}\text { Secondary school students have a less awareness about the } \\
\text { concept of green chemistry }\end{array}$ & Rejected \\
\hline 2. & $\begin{array}{l}\text { Secondary school students have a less awareness about the } \\
\text { daily life application of green chemistry }\end{array}$ & Rejected \\
\hline
\end{tabular}

\section{IMPLICATION OF THE STUDY}

Chemistry is really very helpful to us as its applications are used worldwide for several purposes. We cannot really imagine a world without chemistry and its applications such as medicines. However, we should now concentrate on green chemistry or sustainable chemistry, which refers to reducing or stopping the damage done to the environment around us. Hence, green chemistry could include anything from reducing waste to even disposing of waste in the correct manner.
Another way to save the environment through sustainable chemistry is to make use of renewable food stocks. Yet another good move is to make use of catalysts in experiments rather than using stoichiometric reagents. Chemical derivatives must be avoided as far as possible in any type of application as they often prove to be harmful. All chemical wastes should be disposed of in the best possible manner without causing any damage to the environment and living beings. We have to develop materials that will aid in the infusion of green chemistry into the curriculum such as green chemistry laboratory experiments and short courses on green chemistry. 


\section{International Journal of Engineering Applied Sciences and Technology, 2021 \\ Vol. 6, Issue 3, ISSN No. 2455-2143, Pages 340-345 \\ Published Online July 2021 in IJEAST (http://www.ijeast.com)}

Through this study, the investigator found out that the secondary school students have only an average level of awareness on green chemistry and its daily life applications. In order to create a high level of awareness towards green chemistry and its daily life applications, it must be included in the curriculum as a subject matter for study. Several programs can be conducted for enhancing the students' awareness towards green chemistry.

\section{CONCLUSION}

Green chemistry is not a new branch of science. It is a new philosophical approach that through application and extension of the principles of green chemistry can contribute to sustainable development. Great efforts are still undertaken to design an ideal process that starts from nonpolluting materials. It is clear that the challenge for the future chemical industry is based on production of safer products and processes designed by utilizing new ideas in fundamental research. Furthermore, the success of green chemistry depends on the training and education of a new generation of chemists. Students at all levels have to be introduced to the practice of green chemistry. Finally, regarding the role of education in green chemistry: "The Biggest Challenge of Green Chemistry is to Use its Rules in Practice.

Now environmental pollutions are increasing day by day, we need to use safer chemical substances than chemicals which brings harm to our environment. Sustainable Chemistry or Green Chemistry principles help us to make this environment pollution free.

\section{REFERENCES}

1 Ahluwalia, V. K., \& Kidwai, M. "New Trends in Green Chemistry". Anamaya Publishers: New Delhi, 2004.

2 Agbayewa, J. O., Oloruntegbe, K. O., \& Alake, E. M. "Incorporating green chemistry concepts into the senior

3 secondary school curriculum". In International Journal for Cross-Disciplinary Subjects in Education (IJCDSE), 3

4 (3), 2013.

5 Anastas, P. T., \& WarnerGreen, J. C. "Chemistry: Theory and Practice". Oxford University Press, New York,

61998.

7 Cann, M. C. "Bringing State-of-the-Art, Applied, Novel, Green Chemistry to the Classroom by Employing the

8 Presidential Green Chemistry Challenge Awards". In Journal of Chemical Education, 76, p. 1639, 2005.

9 Clark, J. H. "Green chemistry: Challenges and opportunities". 1999.
10 Clark, J. H. [Ed.] "The Chemistry of Waste Minimization”. Blackie, London, 1995

11 Clark, J. H., Luque, R., Matharu, A. S. "Green Chemistry, Biofuels, and Biorefinery". In Annual Review of

12 Chemical and Biomolecular Engineering, 3:183-207., 2012.

13 Dhage, S. D. "Applications of green chemistry principles in everyday life". International Journal of Research in

14 Pharmacy and Chemistry, 3(3), 518-520, 2013.

15 Farias, L. A., \& Fávaro, D. I. T. "Twenty years of green chemistry: achievements and challenges". In New

16 Chemistry, 34 (2011), pp. 1089-1093, 2011.

17 Haack, J., Hutchison, J. E., Kirchhoff, M. M., \& Levy, I. J. "Going green: Lecture assignments and lab

18 experiences for the college curriculum". In Journal of Chemical Education, 82: 974-978. DOI:

19 10.1021/ed082p974, 2005.

20 Jaiswal, S., Kapoor, D., Kumar, A., \& Sharma, K. (2017). "Applications of green chemistry". In International Journal on Cybernetics \& Informatics (IJCI), 6 (1/2), 127-133. DOI: 10.5121/ijci.2017.6215, 2017.

21 Karpudewan, M., Ismail, Z. H., \& Mohamed, N. "The integration of green chemistry experiments with sustainable development concepts in pre-service teachers' curriculum: Experiences from Malaysia”. In International Journal of Sustainability in Higher Education., 2009.

22 Lancaster, M. (2002). "Green Chemistry: An Introductory Text". In Royal Society of Chemistry, Cambridge,

232002.

24 Lenardão, J. E. et al. "Green chemistry - The 12 principles of green chemistry and its insertion in the teach and

25 research activities". In New Chemistry, 26, pp. 123-129, 2003.

26 Matlack, A. S. "Introduction to Green Chemistry”. Marcel Dekker: New York., 2001.

27 Parrish, A. "Toward the greening of our mind: A new special topics course". In Journal of Chemical Education,

28 84, 245-247, 2007.

29 Sheldon, R. A. "Green solvents for sustainable organic synthesis: State of the art'. In Green Chemistry, 7, 267,

302005.

31 Torok, B. "Green Chemistry: An Inclusive Approach". Amsterdam: Elsevier. P. Ch 3.15., 2017.

32 Trost, B. M. "Atom economy-A challenge for organic synthesis: Homogeneous catalysis leads the way". In 
Published Online July 2021 in IJEAST (http://www.ijeast.com)

33 Chemistry International Education, 34: 259, 1995.

34 Wilson, M. P.; Schwarzman, M. R. "Toward a new U.S. Chemicals policy: Rebuilding the foundation to advance

35 new science, green chemistry, and environmental health", 2009.

36 Woodhouse, E. J., \& Breyman, S. Green Chemistry as Social Movement? Science, Technology and Human

37 Values, 30, pp. 199-222, 2005. 